Note: This is a pre-copy-editing, author-produced PDF of an article accepted for publication in Addiction following peer review. The definitive publisherauthenticated version [O'Farrell A, Allwright S, Downey J, Bedford D, Howell $F$ (2004), The burden of alcohol misuse on emergency in-patient hospital admissions among residents from a health board region in Ireland, Addiction, 99(10), 1279-1285] is available online at http://www3.interscience.wiley.com/journal/118795670/abstract

\title{
The burden of alcohol misuse on emergency in- patient hospital admissions among residents from a health board region in Ireland.
}

\author{
O’Farrell A, Allwright S, Downey J, Bedford D, Howell F.
}

AIMS: To identify in-patient emergency admissions to acute hospitals of residents from a health board region in the Republic of Ireland with an acute alcohol intoxication diagnosis; to profile the admissions and to assess whether the increase in alcohol consumption in Ireland has been mirrored by an increase in alcohol related emergency admissions over the same time period.

DESIGN: A retrospective review of hospital admissions using Hospital In-Patient Enquiry (HIPE) data and alcohol consumption trends using data from the Central Statistics Office (CSO).

SETTING: Acute hospitals in the Republic of Ireland.

PARTICIPANTS: All residents from a health board region admitted with a recorded alcohol intoxication emergency admission to non-private acute hospitals in Ireland. 
MEASUREMENTS: All in-patient emergency admissions for which an acute alcohol intoxication diagnosis (ICD Codes 303.0 and 305.0) was recorded of residents from one health board region were extracted from the Hospital In-Patient Enquiry (HIPE) system for years 1997 to 2001 inclusive. Pearson $\square \cdot$ test was used to compare proportions in groups of categorical data and $\square \cdot$ test for trend was used to identify linear trends: Age standardised rates were calculated for each year and trend analysis carried out. Demographic data on the patients were also extracted from the database.

FINDINGS: There were 3,289 acute alcohol intoxication admissions to acute hospitals of residents from the study region recorded for years 1997 to 2001 inclusive. There were 777 acute alcohol intoxication admissions in 2001 compared to 432 admissions in 1997, an increase of $80 \%$. Age standardised rates showed a significant increasing linear trend $(p<0.001)$. Over half of the admissions occurred on weekends. The average length of stay was 2.7 days (95\% $\mathrm{Cl} 2.5-2.8)$ with just under a quarter (24.3\%) of these admissions being discharged on the same day. The majority of these patients were male $(71.5 \%), 40.9 \%$ were under 30 years old and over half $(59.4 \%)$ were single.

\section{CONCLUSIONS:}

This study shows that alcohol intoxication accounted for a substantial number of emergency in-patient admissions to acute hospitals in one health board region in Ireland and that the age standardised recorded acute alcohol related emergency admission rate increased significantly over the five year period, 1997-2001. This increase mirrored the national increase in alcohol consumption over the same time period. 


\section{INTRODUCTION:}

In Ireland, the harmful effects of alcohol on the population at an individual and societal level have received a great deal of media attention recently. A recent report by the Task Force on Alcohol in Ireland showed that between 1989 and 1999, Ireland had a 41\% increase in alcohol consumption per capita. ${ }^{1}$ Ireland's consumption of alcohol continued to increase in 2000 and Ireland ranked second after Luxembourg for alcohol consumption with a rate of 11.1 litres of pure alcohol per capita compared to the EU average of 9.1 litres of pure alcohol per capita. This increase in consumption has been linked with increased affluence, the relative decline in alcohol taxes and greater access to alcohol through longer opening hours. ${ }^{1}$ Whilst beer continues to dominate the Irish alcohol market, spirit consumption has also increased dramatically from 1.8 litres per capita in 1996 to 2.4 litres per capita in 2001. This increase in spirit consumption is due to the increase in consumption of the relatively new "designer drinks" which are targeted at the young adult market such as "vodka and red bull".

The pattern of drinking is also important for health. ${ }^{2}$ The National Health and Lifestyle Surveys ${ }^{3}$ showed that in Ireland in 1998 younger age groups (18 to 34 years inclusive) drank less often than older age groups but were more likely to engage in binge drinking ( $>70 \mathrm{~g}$ pure alcohol per occasion) when they did drink. A recent survey ${ }^{4}$ carried out on the drinking culture in Irish 18-64 year olds showed that $29 \%$ of the male respondents and $31 \%$ of the female respondents fulfilled the criterion of having risky weekly drinking habits (i.e. exceed the recommended weekly limit) with the risky alcohol consumption being even more concentrated among the 
younger age groups for women than for men. The survey also showed that among those consuming alcohol in Ireland, binge drinking was the norm among men occurring in over $58 \%$ of drinking occasions, and occurring in about a third of drinking occasions for women.

There is evidence that a large number of attendances at Accident and Emergency (A\&E) departments are linked to the acute effects of drinking large amounts of alcohol., ${ }^{5,6}$ Furthermore, several ecological studies have shown that high per capita alcohol consumption is associated with specific alcohol related health outcomes such as oral cancer and liver disease..$^{7-11}$ However, it is not known whether high per capita alcohol consumption is also associated with emergency in-patient acute alcohol intoxication admissions to hospital.

\section{Aim:}

The aim of this study was to identify in-patient emergency admissions to acute hospitals of residents from a health board region in Ireland with an acute alcohol intoxication diagnosis; to profile these admissions and to assess whether the increase in alcohol consumption in Ireland has been mirrored by an increase in alcohol intoxication emergency admissions over the same time period.

\section{Methods:}

All recorded acute alcohol intoxication emergency admissions as defined by the International Classification of Diseases (ICD-9-CM) codes 303.0 and 305.0 of residents from one health board region for years 1997 to 2001 were 
extracted from the Irish Hospital In-Patient Enquiry (HIPE) system. HIPE is a computer-based health information system designed to collect national data on discharges from acute general hospitals in Ireland. Therefore only inpatient admissions with a hospital discharge record are included in this study (patients who attend A\&E emergency rooms but are not admitted on to a ward are not included). All in-patient admissions with any diagnosis (any one of up to six possible diagnoses) of acute alcohol intoxication were included. Acute alcohol intoxication is classified in the International Classification of Disease, version 9 (ICD-9) as "acute drunkenness in alcoholism"(ICD Code 3030) and/or alcohol abuse (ICD Code 3050) which includes "drunkenness" not otherwise specified (NOS); "excessive drinking of alcohol NOS"; "hangover (alcohol)"; and "inebriety NOS". ICD codes 3030 includes alcohol intoxication in alcoholism. ICD code 3050 includes non-dependent alcohol abuse and drunkenness.

To calculate the age and sex profile of the patients, estimates of numbers of patients, as distinct from numbers of admissions were obtained by matching medical record number and date of birth. However, some repeat admissions may have been missed if a patient was admitted to different hospitals over the study period and was therefore given a different medical record number. Admissions prior to 1997 were excluded as the data were considered unreliable and coverage poor. Data collection improved considerably from 1997 onwards due to improved training and a standardised approach, and coverage increased to $95 \% .^{12}$ Denominators were extracted from the Public Health Information System (PHIS) ${ }^{13}$ which 
includes censal and inter-censal population data from the Central Statistics Office of Ireland.

Alcohol consumption per capita was collected from the Central Statistics Office ${ }^{14}$ for years 1997 to 2001 to examine trends in alcohol consumption over the study period. Data on beer, wine and spirit consumption was collected and converted into litres of pure alcohol using standardised conversion rates. ${ }^{15}$

To test completeness of the HIPE recording data, 100 non-alcohol related emergency admissions of health board residents to the local acute hospital were extracted randomly from HIPE for 1997 and for 2000. The medical records of these patients were retrieved from this hospital and examined to ascertain what proportion of patients who were drunk on admission were misclassified as non-alcohol related.

The data were analysed using JMP statistical package. ${ }^{16}$ Crude and age-adjusted rates and rate differences were calculated using StatsDirect. ${ }^{17}$ Pearson $\square$ test was used to compare proportions in groups of categorical data and $\square$. test for trend was used to identify linear trends.

\section{Results:}

\section{Number of acute alcohol related admissions by year:}

There were 3,289 acute alcohol related admissions to acute hospitals of residents during the study period 1997 to 2001 inclusive. The majority of these admissions $(2,799 ; 85.1 \%)$ had ICD code 3050 , the remainder (490; $14.9 \%$ ) had ICD code 3030; this proportion did not change significantly over the study period. As there was an increase in both these acute alcohol 
intoxication diagnoses and as the ratio of ICD code 3030 to ICD code 3050

did not change significantly over time, these two admission codes were

analysed together for the purposes of this study.

Table 1. Number and rate of acute alcohol intoxication (ICD 3030 and 3050) admissions of health board residents by year of admission.

\begin{tabular}{|c|c|c|c|c|c|c|}
\hline $\begin{array}{l}\text { Year of } \\
\text { Admission }\end{array}$ & $\begin{array}{l}\text { Total } \\
\text { Emergency } \\
\text { Admissions }\end{array}$ & $\begin{array}{l}\text { Acute } \\
\text { Alcohol } \\
\text { Emergency } \\
\text { Admissions }\end{array}$ & $\begin{array}{l}\% \text { of All Emergency } \\
\text { Admissions that were } \\
\text { Acute Alcohol Related } \\
(95 \% \mathrm{Cl})\end{array}$ & $\begin{array}{l}\text { Acute Alcohol } \\
\text { Admissions } \\
\text { per } 100,000 \\
\text { population } \S\end{array}$ & $\begin{array}{l}\text { Age Standardised } \\
\text { Rate* } \\
\text { of Acute Alcohol } \\
\text { Admissions per } \\
100,000 \text { population } \\
(95 \% \mathrm{Cl})\end{array}$ & $\begin{array}{l}\text { Alcohol } \\
\text { consumption per } \\
\text { adult (aged } 15 \\
\text { yrs and over) in } \\
\text { litres of pure } \\
\text { alcohol } \\
\end{array}$ \\
\hline 1997 & 28920 & 432 & $\begin{array}{l}1.5 \\
(1.3-1.6)\end{array}$ & 138.6 & $\begin{array}{l}144.3 \\
(130.6-158.0)\end{array}$ & 12.8 \\
\hline 1998 & 29535 & 550 & $\begin{array}{l}1.9 \\
(1.7-2.0)\end{array}$ & 173.4 & $\begin{array}{l}179.7 \\
(164.6-194.8)\end{array}$ & 13.1 \\
\hline 1999 & 32832 & 685 & $\begin{array}{l}2.0 \\
(1.9-2.2)\end{array}$ & 212.2 & $\begin{array}{l}218.7 \\
(202.2-235.6)\end{array}$ & 13.8 \\
\hline 2000 & 34795 & 845 & $\begin{array}{l}2.4 \\
(2.3-2.6)\end{array}$ & 261.8 & $\begin{array}{l}271.3 \\
(252.9-289.6)\end{array}$ & 14.2 \\
\hline 2001 & 36689 & 777 & $\begin{array}{l}2.1 \\
(2.0-2.3)\end{array}$ & 230.9 & $\begin{array}{l}238.3 \\
(221.5-258.1)\end{array}$ & 14.5 \\
\hline $\begin{array}{l}\text { (1997-2001 } \\
\text { inclusive) }\end{array}$ & 162771 & 3289 & $2.0(1.9-2.1)$ & 203.4 & & \\
\hline
\end{tabular}

Chi-squared test for trend on acute alcohol emergency admissions, $p<0.001$.

$\S$ Denominators: censal and intercensal data from Public Health Information System (PHIS), Central Statistics Office.

*Standard population: 2002 Census Data, Ireland.

${ }^{* *}$ Revenue Commissioners and Central Statistics Office, Annual Reports

Table 1 shows that there were 777 acute alcohol intoxication admissions in 2001 compared to 432 admissions in 1997, an increase of $79.8 \%$. The proportion of all emergency admissions that were acute alcohol intoxication related increased significantly from $1.5 \%(95 \% \mathrm{Cl} 1.3$ to 1.6$)$ in 1997 to $2.1 \%$ (95\% $\mathrm{Cl} 2.0$ to 2.3 ) in 2001. The age standardised rate also increased significantly from 144.3 per 100,000 to 238.3 per 100,000 over this time period ( $\square \square$ test for trend, $p<0.001$ ). The per adult (aged 15 years and over) 
alcohol consumption (in litres of pure alcohol) rate increased by $13.2 \%$ from 12.8 litres in 1997 to 14.5 litres in 2001 . The increase in the age standardised acute alcohol intoxicated related emergency admission rate mirrors the rise in alcohol consumption over the same time period. (Figure 1).

Figure 1. Age standardised acute alcohol intoxication emergency admissions (ICD Codes 3030 and 3050) and per adult (15 years and over) alcohol consumption (in litres pure alcohol) by year, Republic of Ireland.

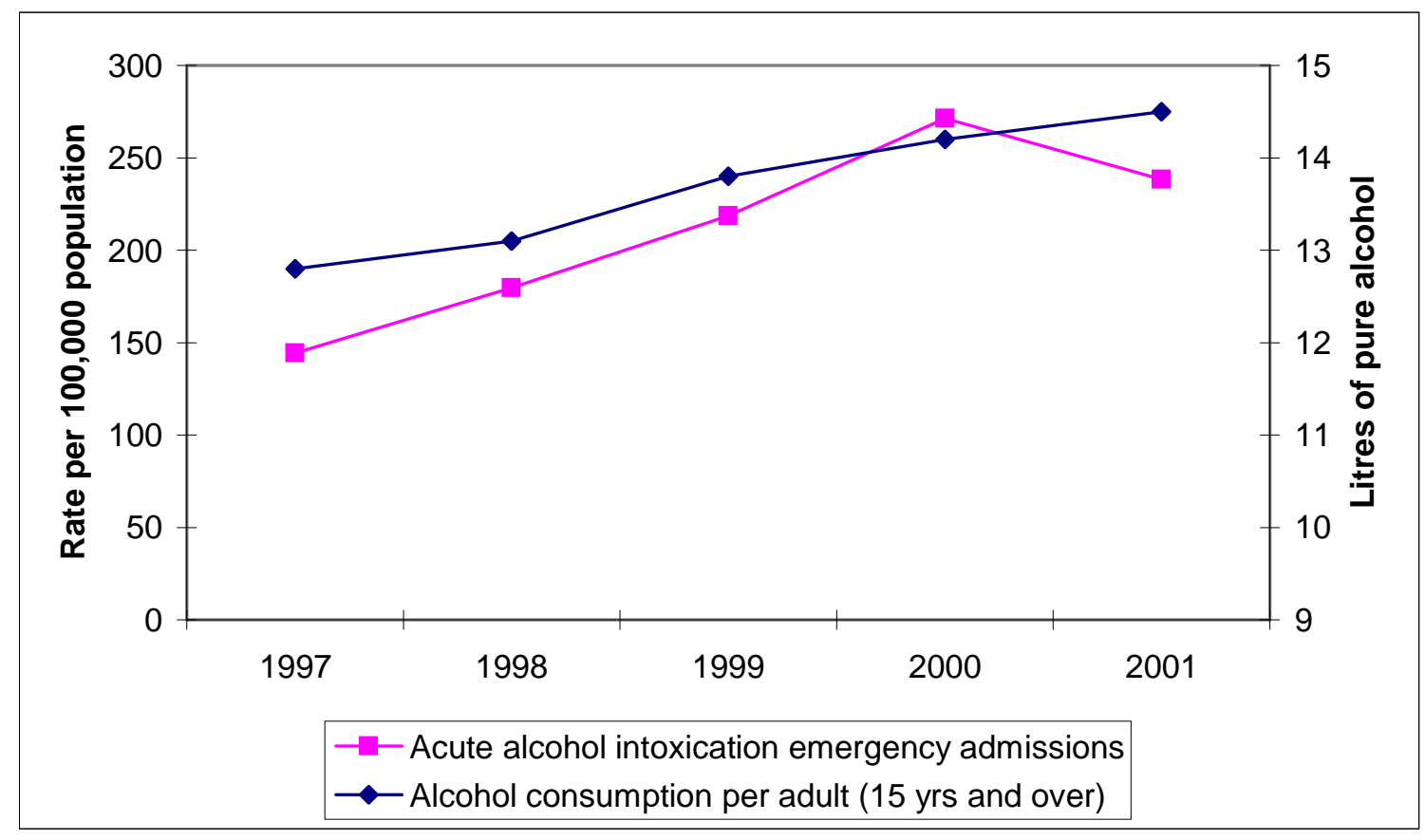

* Chi-squared test for trend on acute alcohol emergency admissions, $p<0.001$.

\section{Age and gender of patients admitted with acute alcohol diagnoses}

The 3,289 acute alcohol admissions related to 2,731 individuals, i.e. 558 (16.9\%) were repeat admissions (the same person admitted with an acute alcohol related diagnosis twice or more over the study period). A high proportion of the patients were young with 1,193 (43.6\%) under the age of 30 years. Over ten per cent $(300,10.9 \%)$ of the patients were under 18 years of age and $83(3.0 \%)$ were aged $10-14$ years. Males accounted for 
the majority $(1,968,72.0 \%)$ of these admissions and the median age of male patients was significantly higher than that of the female patients (36.1 yrs vs 28.6 yrs, $p<0.001$ ). Figure 2 shows the age profile by gender of the patients ( $N=2,731)$ over the study period. Almost half $(372,48.8 \%)$ of the 763 female patients admitted with an acute alcohol diagnosis were between 10-29 years of age and 800 of the 1,968 (40.6\%) male patients were between 10-29 years of age. Over half (59.4\%) of the patients admitted with an acute alcohol diagnosis were single with almost one quarter (24.2\%) married.

Figure 2. Age profile of male and female health board residents admitted to acute hospitals with acute alcohol intoxication diagnoses (ICD codes 3030 and 3050) during study period 1997-2001.

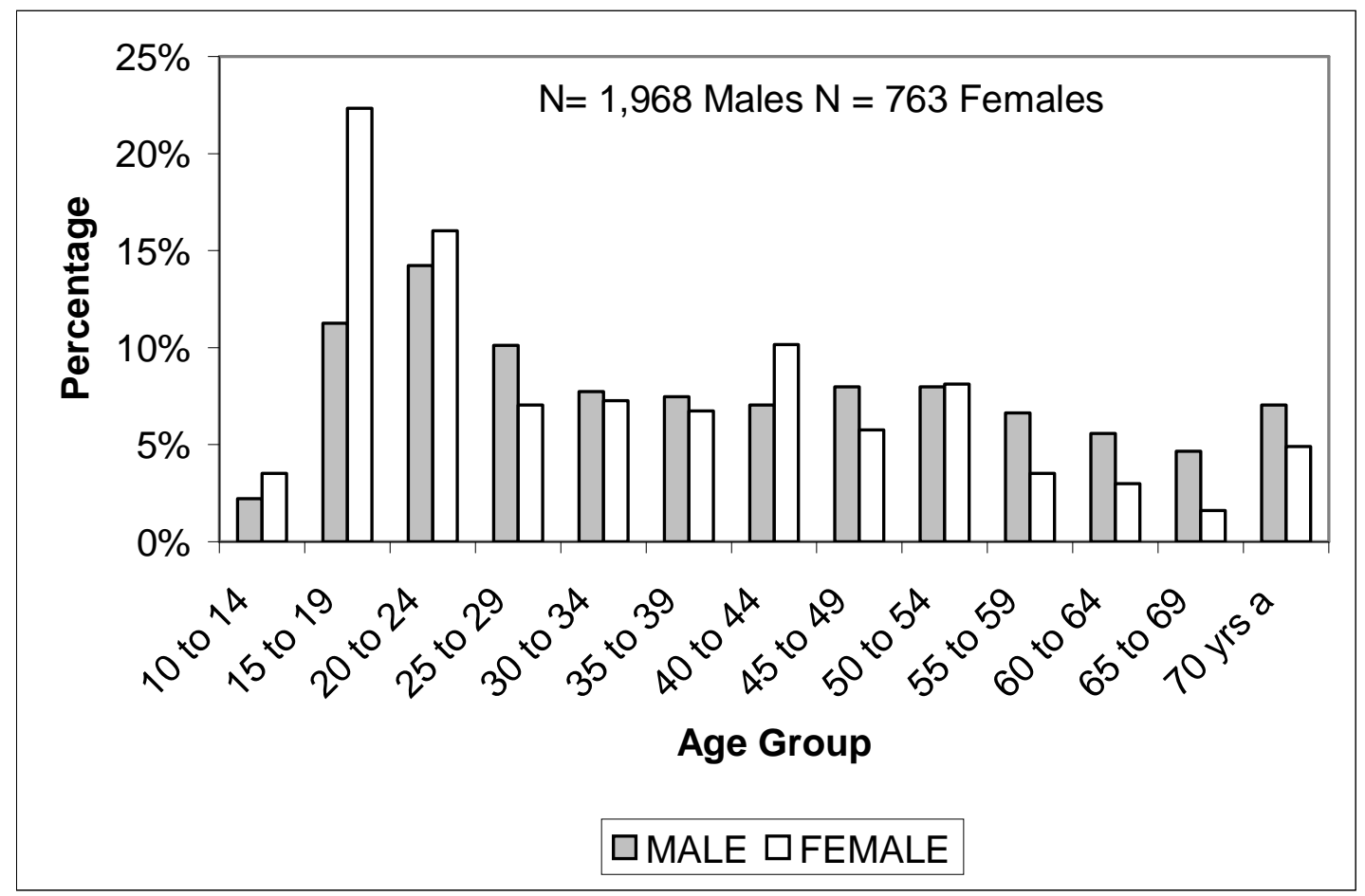


The age specific rates increased over time for each age group (Figure 3).

There was a marked increase for all the age groups except the youngest

(10-19 years) and the oldest ( $70+$ years) age groups.

Figure 3. Age-specific rates for all acute alcohol intoxication emergency admissions (ICD Codes 3030 and 3050) of residents from a health board region in Ireland by year of admission.

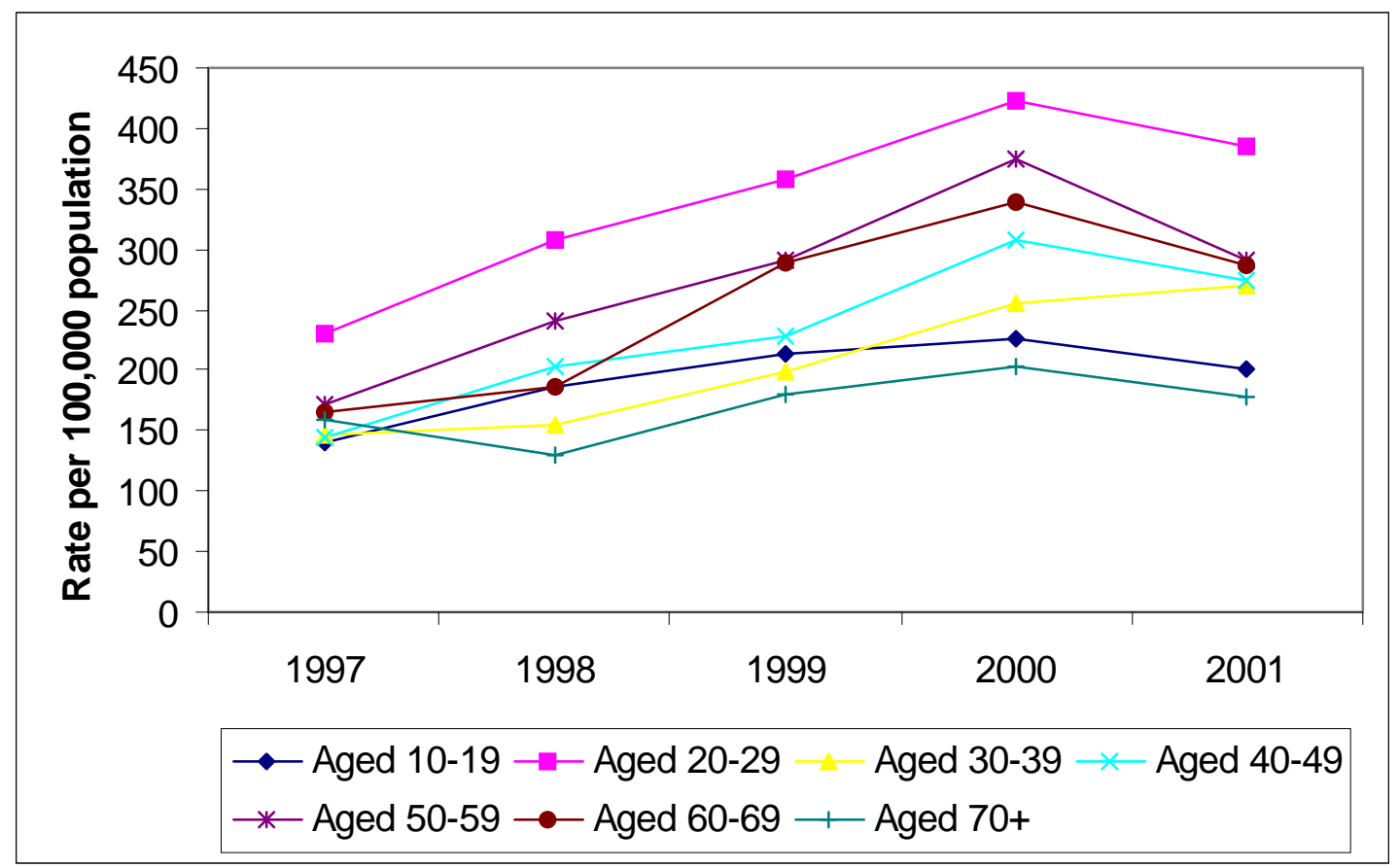

Figures $4 \mathrm{a}$ and $4 \mathrm{~b}$ shows age-specific rates for the two ICD codes separately. The highest age specific rates for ICD code 3050 (which includes non-dependent alcohol abuse and drunkenness) was seen in the younger 20-29 year age group (Figure 4a). In contrast, the highest age specific rates for ICD code 3030 (which includes alcohol intoxication in alcoholism) was in the three oldest age groups (40-49, 50-59 and 60-69 years) (Figure 4b). 
Figure 4a. Age-specific rates for ICD Code 3050 (which includes nondependent alcohol abuse and drunkenness) acute alcohol intoxication emergency admissions of residents from a health board region in Ireland by year of admission.

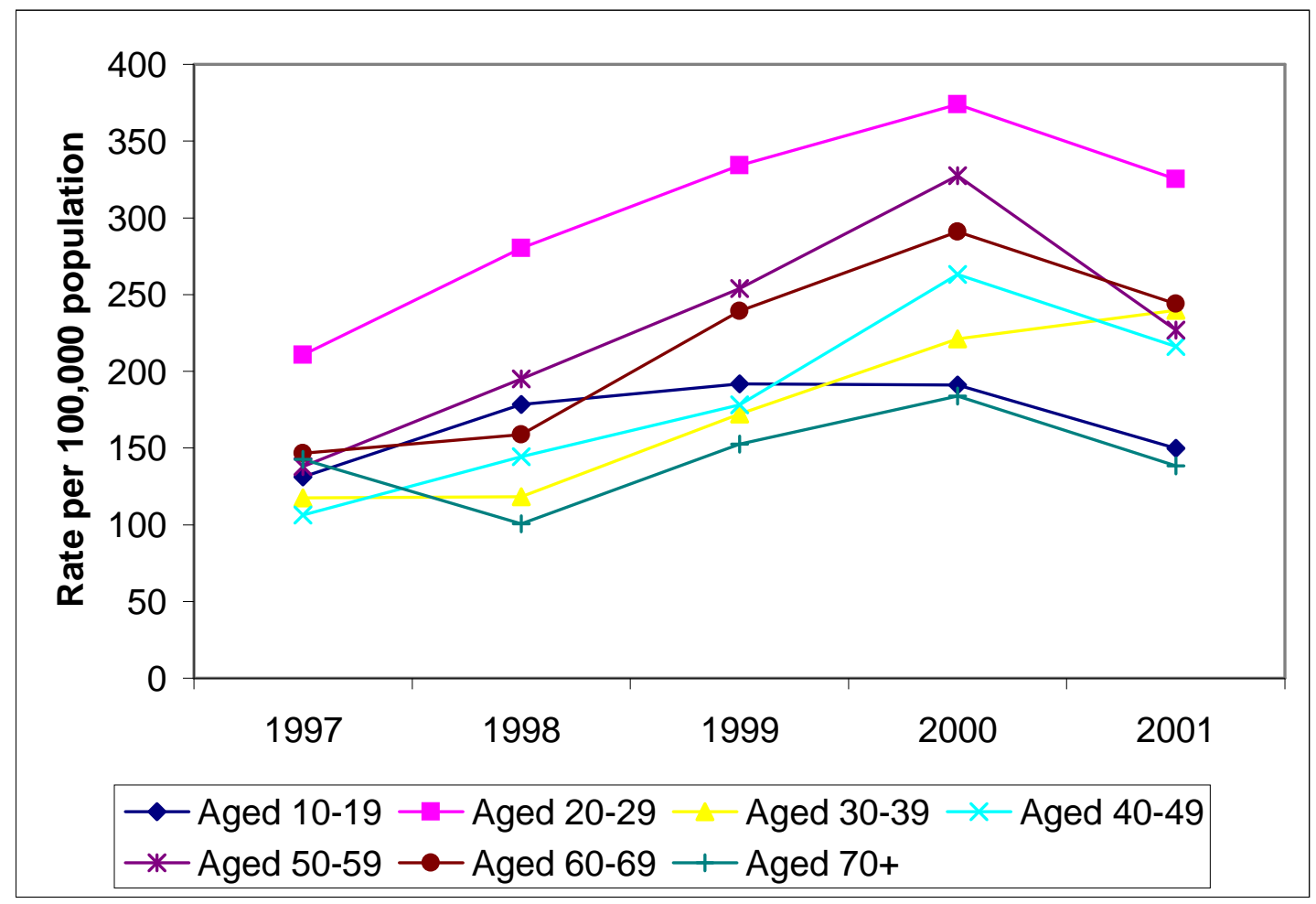

Figure 4b. Age-specific rates for ICD Code 303.0 (which includes alcohol intoxication in alcoholism and alcohol intoxication in alcohol dependence) emergency admissions of residents from a health board region in Ireland by year of admission.

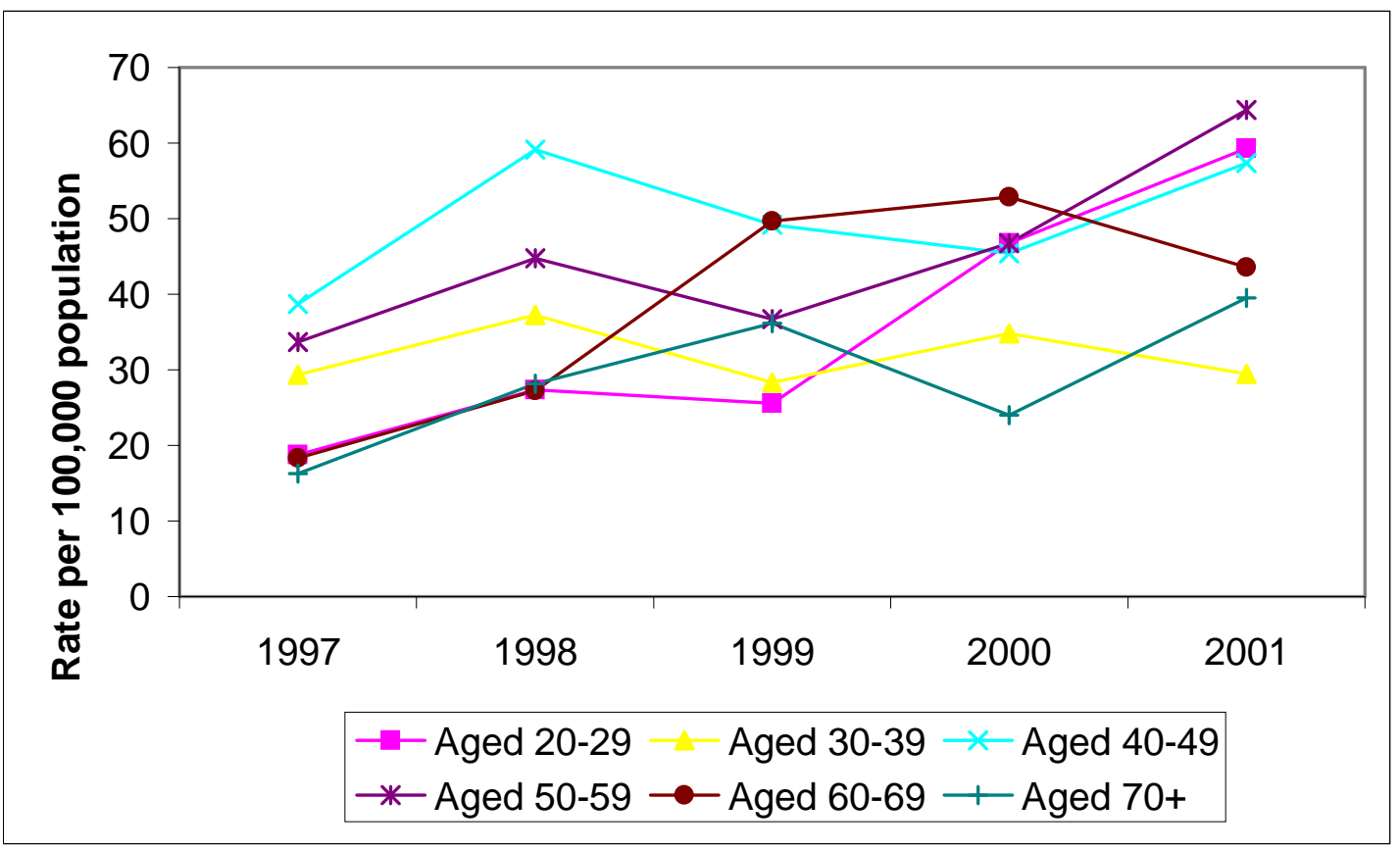




\section{Principal diagnoses:}

The five most frequently recorded principal diagnoses for the acute alcohol intoxication emergency admissions are listed in Table 2. Together, these five diagnoses account for one third (1096) of the 3,289 principal diagnoses for acute alcohol admissions. Thirteen per cent of these admissions had a principal diagnosis of alcohol abuse, eight per cent had a principal diagnosis of syncope and collapse and 12 per cent were related to head injury.

Table 2. Five most frequently recorded principal diagnoses for acute alcohol intoxication emergency admissions (ICD codes 3030 and 3050), 1997-2001.

\begin{tabular}{|llcc|}
\hline ICD Code No. & Principal Diagnosis & No. & Percentage \\
30500 & Alcohol abuse & 416 & 12.6 \\
7802 & Syncope and Collapse & 268 & 8.1 \\
45901 & Head Injury NOS* & 187 & 5.7 \\
8501 & Concussion-Brief Coma & 113 & 3.4 \\
85401 & Brain Injury-NEC**-No Coma & 112 & 3.4 \\
Various & Others & 2,193 & 66.8 \\
& Total & 3,289 & 100.0 \\
\hline
\end{tabular}

* Not Otherwise Specified $\quad{ }^{* *}$ Not Elsewhere Classified

\section{Profile of acute alcohol hospital admissions:}

The majority of the 3,289 admissions occurred during the weekend with over 60 per cent occurring between Saturday and Monday inclusive (Figure 5). 
Figure 5. Proportion of acute alcohol intoxication admissions (ICD Codes $3030 \& 3050$ ) by day of admission.

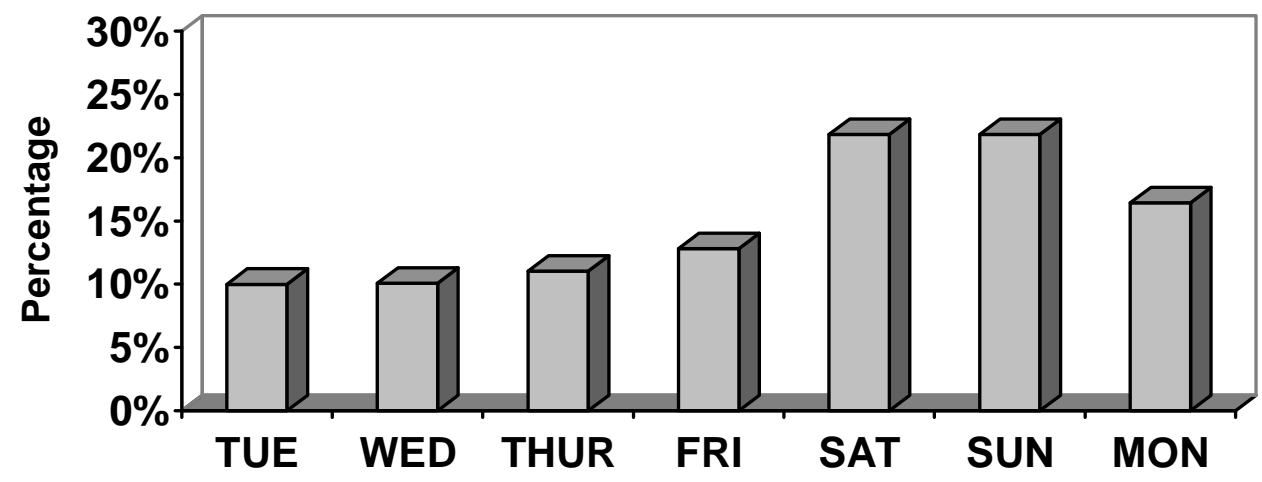

The mean length of stay was 2.7 days $(95 \% \mathrm{Cl} 2.6$ to 2.9 days) with a median length of stay of 1 day (range 0-102 days). Eight hundred (24.3\%) of these admissions were discharged on the same day as the admission day. Although most of these admissions were of short duration, these admissions accounted for 8,950 bed days.

The majority of the admissions, 2,680 (81.5\%) were discharged home, 431 (13.1\%) self-discharged, 123 (3.7\%) were transferred to other hospitals, 39 (1.2\%) were sent to long stay accommodation, $14(0.4 \%)$ died, and $2(0.1 \%)$ had no recorded discharge code.

\section{Completeness of HIPE recording/coding:}

In the review of 100 randomly selected non-alcohol related emergency admissions records in 1997 and 100 in during 2000 it showed that in 1997 recording of alcohol intoxication was missed in $4 \%$ of the 100 randomly selected admissions (i.e. acute alcohol intoxication/drunkenness was 
mentioned in the notes but not recorded/coded in the HIPE record) and in 2000 alcohol intoxication was missed in HIPE for $8 \%$ of the cases.

\section{DISCUSSION:}

This study has shown that there has been an increase in both the number and rate of recorded acute alcohol intoxication admissions in this study population over the five year period studied. Neither the rise in population nor a change in age structure of the population in the health board region accounts for this increase. Examination of 200 medical records showed that the proportion of non-alcohol admissions, where alcohol recording was missed was higher in 2000 than in 1997 (4\% in 1997 and 8\% in 2000). This suggests that better recording/coding of acute alcohol diagnoses (ICD 3030 and 3050) over time by the HIPE coders did not explain the increase. The reason for the small decrease in admissions from 2000 to 2001 is unknown and could be due to chance or it could be due to dis-improvement in the recording of acute alcohol intoxication by the HIPE coders over time as indicated by the validation exercise on the randomly selected medical records. Further examination of medical records in subsequent years is required to check for this.

The increase in recorded acute alcohol intoxication admissions corresponds to an increase in alcohol consumption levels that has occurred over the same time period. Hospital admissions for acute alcohol intoxication rose by almost $80 \%$ over the study period, the corresponding rise in alcohol consumption per adult consumption was more modest at $13.2 \%$ over the same time period. The level of alcohol related harm in a population derives 
from the pattern of that population's drinking as well as the overall level of consumption. The single population theory, as propounded by Skog ${ }^{18}$ and Rose $^{19}$, and others ${ }^{20}$ states that the distribution of alcohol consumption moves up or down as a whole and that drinking behaviour is under "collective influence" which suggests that any increase in mean consumption is likely to lead to an increase in the prevalence of heavy drinking. Furthermore, there is a high alcohol abstention rate in Ireland (approximately $23 \%$ ) which did not change over the study period ${ }^{4}$, suggesting that the recent increase in per adult alcohol consumption in Ireland cannot be explained by the decline in abstention rates. Thus, the same number of people are drinking alcohol but drinkers are drinking more alcohol on occasion and therefore the proportion of people drinking at harmful levels is likely to have increased quite significantly over the study period. This increase is under-represented by the overall per capita trends. We have also shown that $41 \%$ of the acute alcohol intoxication admissions were in young people (under 30 years), mostly occurred at weekends and that the highest rate of admissions for the non-dependent alcohol abuse and drunkenness (ICD code 3050) was in the 20-29 ear olds (see Figure 4a). This is consistent with the survey by Ramstedt and Hope ${ }^{4}$ which showed that the highest self-reported alcohol consumption was among 18-29 year olds in Ireland and the prevalence of binge drinking was very high among younger age groups. Therefore, effective policy measures to tackle the pattern of binge drinking and to promote healthy drinking as well as policies regulating availability through access, pricing and promotion, as recommended by the Strategic Task Force on Alcohol ${ }^{1}$ are required to 
minimise the harmful affects of alcohol within Irish society. In particular, strategies for the care of these patients in acute hospitals where they pose serious issues for risk management, resource utility and the quality of care for other patients need to be considered.

Unlike previous studies which reported on the prevalence of alcohol abuse in general hospital populations, ${ }^{21,22}$ and studies which looked at per capita consumption and other alcohol related health outcomes, ${ }^{6-9}$ this study looked at the impact of acute alcohol intoxication only (i.e drunkenness only) on all in-patient emergency admissions to acute hospitals. This was done by limiting the study to those patients who had an emergency admission with an acute alcohol intoxication diagnosis (ICD codes 3030 and/or 3050 only) mentioned. The majority of these admissions occurred during the weekend and this peak in admissions may reflect the higher prevalence of harmful drinking that occurs over the weekend period.

The average length of stay was 2.7 days for these patients and therefore the effect of these admissions on hospital resources is considerable. It is worrying that almost half $(41 \%)$ of these admissions were for individuals under 30 years of age, while almost $10 \%$ were under 18 years of age. This indicates the ready availability of alcohol to our young population. The younger average age of the female admissions is of concern in terms of the future health of this group.

\section{LIMITATIONS OF THE STUDY:}

As no measure of alcohol blood level was available, recording of acute alcohol intoxication on the patient chart was used in this study as an indirect 
measure of patients who were drunk on admission. However, given that $41 \%$ of these admissions were of young people, that they occurred mostly at the weekend, and with principal diagnoses associated with the effects of harmful drinking, it is likely that these admissions are a reliable indicator of emergency admissions of patients who were intoxicated on admission and therefore most likely to be harmful drinkers.

Although this study is based on just one health board region in Ireland, the area represents an area of mixed social class with a demographic profile similar to that of the rest of Ireland ${ }^{23}$. Therefore, it is reasonable to assume that these patterns are repeated in the other nine health boards in the Republic of Ireland.

\section{Conclusion:}

This study shows that there has been a real increase in the number and age standardised rate of recorded acute alcohol intoxication in-patient admissions to acute hospitals in this health board region in the Republic of Ireland over time. This increase mirrors the corresponding increase in alcohol consumption in Ireland over the same time period. A worrying aspect is the number of under-age drinkers admitted over the study period. At a time of limited resources, the burden of patients being admitted with an acute alcohol diagnosis (i.e. drunk on admission) to Irish acute hospitals is quite considerable and illustrates that alcohol abuse is not only having an effect on A\&E admissions as previously shown ${ }^{5-6}$ but that alcohol abuse is severe enough to require a considerable number of patients needing to be admitted as emergency in-patients. Effective alcohol policy measures, such 
as those recommended in the Strategic Task Force on Alcohol Interim Report, ${ }^{1}$ are urgently required to control both the rise in alcohol consumption and to modify the high risk drinking patterns in Irish society. 


\section{REFERENCES:}

1. Strategic Taskforce on Alcohol Interim Report (2002). Department of Health and Children, Dublin, Ireland

2. Rehm J, Ashley MJ, Room R, Single R, Bondy S et al (1996). On the emerging paradigm of drinking patterns and their social and health consequences. Addiction, 91(11): 1615-1621.

3. Friel S, Nic Gabhainn S and Kelleher C. (1999). The National health and Lifestyle Surveys (SLAN, HSBC). Centre for Health Promotion Studies, National University of Ireland, Galway.

4. Ramstedt M and Hope A. (2003). The Irish Drinking Culture:

Drinking and drinking-related harm, a European comparison. Department of Health and Children, Dublin, Ireland

5. Pirmohamed M, Brown C, Owens L, Luke C, Gilmore IT, Breckenridge AM, and Park BK. (2000). The burden of alcohol misuse on an inner-city general hospital. Quarterly Journal of Medicine, 93: 291-295.

6. Waller S, Thom B, Harris S and Kelly M. (1998). Perceptions of alcohol-related attendances in accident and emergency departments in England: a national survey. Alcohol and Alcoholism, 33: 354-361.

7. Rehm J, Gmel G, Room R and Frick U. (2001). Average volume of alcohol consumption, drinking patterns and related burden of mortality in young people in established market economies in Europe. Eur. Addict. Res., Aug 7 (3): 148-151. 
8. Gutjahr E, Gmel G and Rehm J. (2001). Relation between average alcohol consumption and disease: an overview. Eur. Addict Res., Aug 7 (3): 117-127.

9. Rehm J, Room R, Graham K, Monteiro M, Gmel G and Sempos CT. (2003). The relationship of average volume of alcohol consumption and patterns of drinking to burden of disease: an overview. Addiction, Sep; 98(9): 1209-1228.

10. Skog OJ. (1987). Trends in alcohol consumption and deaths from diseases. Br. J. Addict., Sep; 82(9): 1033-1041.

11. English D, Holman D. (1995). The Quantification of Drug Caused Mortality in Australia 1992. Commonwealth Department of Human Services and Health, Canberra, Australia.

12. Department of Health and Children (2002). Activity in Acute Public Hospitals in Ireland 1990-1999. ESRI, Dublin.

13. Public Health Information System (PHIS). (2002). Information Management Unit, Department of Health and Children.

14. Annual Reports of the Central Statistics Office (1998-2002). Central Statistics Office, Dublin.

15. World Health Organisation (2000). International Guide for Monitoring Alcohol Consumption and Related Harm. Department of Mental Health and Substance Dependence, WHO, Geneva.

16. SAS Institute 2001. JMP Statistical Package. Version 4, Cary NC, USA.

17. StatsDirect Ltd 2003. StatsDirect, Version, 2.2.9, Cheshire, U.K. 
18. Skog OJ (1985). The collectivity of drinking cultures: a theory of the distribution of alcohol consumption. Br. J. Addict., 80: 83-99.

19. Rose $G$ and Day S. (1990). The population mean predicts the number of deviant individuals. BMJ, 301: 1031-1034.

20. Colhoun H, Ben-Shlomo Y, Dong W, Bost L and Marmot M. (1997). Ecological analysis of collectivity of alcohol consumption in England: importance of the average drinker. BMJ, 314: 1164

21. Green M, Setchell J, Hames P, Stiff G, Touquet R, and Priest R. (1993). Management of alcohol-abusing patients in accident and emergency departments. Journal of the Royal Society of Medicine, 86: 393-395.

22. Hearne R, Connolly A and Sheehan J. (2002). Alcohol abuse prevalence and detection in a general hospital. Journal of the Royal Society of Medicine, 95: 84-87.

23. Health Status in the North Eastern Health Board (NEHB) Ireland. Department of Public Health, NEHB, Ireland. (2000). 